\title{
ENTRE POSSIBILIDADES E A REALIDADE DA RELAÇÃO FAMÍLIA E ESCOLA NO MUNICÍPIO DE CAMETÁ-PA
}

MENDONÇA, Aliny Cristina Nunes ${ }^{1}$

\section{Resumo}

O presente artigo versa "Entre possibilidades e a realidade da relação família e escola no município de Cametá-PA", objetivamos com isto, Refletir as tessituras da relação família e escola considerando os desafios atuais na construção de uma escola democrática. Essa reflexão é necessária por entendermos que somente a partir da construção de uma relação dialógica e crítica, família e escola poderão lograr de resultados com maior qualidade na educação. Metodologicamente trabalhamos com a abordagem qualitativa, pois nossa finalidade foi traçar um panorama da relação família e escola nos dias atuais no município de Cametá. A partir da pesquisa de campo que teve como primeira etapa o levantamento bibliográfico e a seleção do referencial teórico e como segunda etapa a entrevista com pais e professores, foi possível perceber a compreensão que os entrevistados possuem sobre a relação família e escola. Foram entrevistados 13 pais e/ou responsável de alunos e 6 professores que para manter suas identidades em sigilo, foram identificados como $\mathrm{F}$ para as famílias acrescentando-se apenas números para diferenciar os 13 entrevistados e PF para os professores no mesmo moldes. Constatamos que ainda existem muitos obstáculos a serem superados para que a relação família e escola se efetive como ato democrático e participativo, entretanto, mudanças forma de ver a escola por parte dos pais e/ou responsáveis e dos professores em perceber de como deve ser a participação das famílias na escola apontam para a efetivação da gestão democrática como princípio, não apenas teórico, mas também prático da escola.

Palavras-Chave: Educação. Gestão Democrática. Relação Família e Escola.

\section{INTRODUÇÃO}

O desenvolvimento e a participação da Família no ambiente escolar nos dias atuais são considerados componentes importantes para o desenvolvimento integral dos alunos no que tange ao processo ensino-aprendizagem. Nesse sentido, se faz necessário um repensar da forma como escola e família vem se relacionando e atuando no processo educacional dos sujeitos.

Ao longo dos tempos como se pode verificar a partir da leitura especializada da área, a família fora excluída do contexto educacional, fosse pela centralidade do

\footnotetext{
1 Servidora pública vinculada a Prefeitura Municipal de Cametá-Pa, através da Secretaria de Educação. Possui Graduação em Pedagogia pela Universidade do Vale do Acarau - UVA; Especialista e Gestão, Supervisão e Orientação Escola pelo Centro Universitário Leonardo Da Vinci; Especialista em Educação do Campo pela Universidade Federal do Pará; Especialista em Psicopedagogia com ênfase em Educação Inclusiva pela Faculdade de Patrocínio - FAP; Mestra em Ciências da Educação pela Facultad Internamericana de Ciencias Sociales (FICS)
} 
conhecimento científico socialmente válido nela contido, fosse pela ausência dos pais que necessitavam trabalhar duras jornadas de trabalho para manter o sustento dos que iam para a escolar. O histórico de abandono escolar no Brasil é bastante significativo, pois foi resultado da falta de oportunidade e da condição de vida precária que as famílias enfrentavam, o que os levava a escolher entre a possibilidade de conseguir algum tipo de trabalho para manter seu sustento ou estudar.

Há de se ressaltar ainda, que por muito tempo a família não acreditava na escola como instituição capaz de contribuir para a transformação da realidade social, pois, a formação era um processo lento e as necessidades de manter o sustento de muitas famílias era urgente. Dessa forma, a maior parte dos filhos dos trabalhadores eram levados a fracassar na vida escolar e repetir os destinos de seus antepassados, dada a falta de apoio e incentivo das famílias para a educação. Com vistas aos novos tempos e possibilidades para a relação família e escola, objetivamos nesse artigo: Refletir as tessituras da relação família e escola considerando os desafios atuais na construção de uma escola democrática.

Esse artigo é resultado da dissertação de mestrado intitulada "AS TRANSFORMAÇÕES SOCIOEDUCACIONAIS: A RELAÇÃO FAMÍLIA-ESCOLA NO PROCESSO DE APRENDIZAGEM" apresentada ao Programa de PósGraduação em Ciências da Educação da Facultad Internamericana de Ciencias Sociales (FICS). Sendo assim para a construção da metodologia desse estudo, adotamos a abordagem qualitativa pautada no diálogo e análise crítica da realidade, no que tange aos procedimentos técnicos trabalhamos com a pesquisa de campo, subsidiada por elementos de natureza bibliográfica. Na primeira etapa realizamos o levantamento bibliográfico e seleção do referencial teórico, já na segunda etapa coletamos os dados por meio de entrevista com pais e responsáveis de alunos e professores, selecionando e apresentado no corpo desse artigo somente as que mais se destacaram.

Constatamos assim, que para a construção de uma escola alinhada de fato aos princípios democráticos a relação família e escola deve acontecer e se tornar algo natural, comum e participativo, pois os pais e responsáveis precisam ter autonomia para participar das atividades escolares, indo além das participações e eventos formais, ou de interesse da gestão da escola (reunião, convocatória, entre outros). Os pais e responsáveis devem participar da vida escolar dos filhos por 
entender que é importante e que muito podem contribuir com a qualidade da educação e não apenas porque a escola cobra sua participação nas atividades que estabelecem em seus cronogramas.

\section{A CONSTITUIÇÃO HISTÓRICA DA RELAÇÃO FAMÍLIA E ESCOLA}

Quando se faz uma leitura histórica a respeito do conceito de família, percebe-se que este vem sendo ao longo dos tempos lentamente alterado das as concepções teórico-ideológicas que vem sendo construídas ou ainda os dispositivos legais, como por exemplo, a Constituição Federal que amplia o debate sobre o termo e traz novas formulações no campo prático do termo. Nesse sentido, podemos considerar que a família é uma instituição que vem sendo construída ao longo dos tempos, dado que as transformações sociais no que tange até mesmo as relações de trabalho tem promovido mudanças significativas no papel social que cada sujeito desempenha nesse espaço denominado de família.

Numa concepção generalista, entendemos família como sendo um agrupamento de pessoas que dão sentido a um grupo social que tem como vínculo principal as questões genéticas, ou melhor, sanguíneas. Nota-se que esse conceito mais geral de família se liga diretamente as questões biológicas, de modo que não leva em consideração questões sociais e afetivas. Fazendo uma análise histórica do conceito de Família, Picanço (2012, p. 08) considera que:

\footnotetext{
O termo família é derivado do latim famulus, que significa 'escravo doméstico'. Este termo foi criado na Roma Antiga para designar um novo grupo social que surgiu entre as tribos latinas, ao serem introduzidas à agricultura e também escravidão legalizada. No direito romano clássico a 'família natural' cresce de importância, esta família é baseada no casamento e no vínculo de sangue.
}

As considerações de Picanço (2012) relevam que em sua origem o termo "Família", referia-se à situação escravista a qual eram submetidos muitos sujeitos. Vale ressaltar que mesmo dentro dessa perspectiva, já se defendia ou pelo menos era gestada a concepção de família no que tange o enlace entre pessoas por meio do matrimônio e/ou aqueles que tinham relação de parentesco por questões sanguíneas.

Nesse sentido é que se toma ainda sobre foco de análise o Século $X V$, considerado como Período Medieval, no qual a concepção de família era ligada essencialmente ao patriarcalismo sem que se pudesse levar em consideração o 
romantismo, sentimentalismo, questões afetivas e de cuidado. Nesse período em particular, segundo Demenech (2013) a família era entendida como "natural" ou "nuclear" é formada pelos cônjuges e seus filhos.

Airès (2006) em suas reflexões históricas sobre a relação família-escola, considera que a concepção sobre o termo família foi sendo gradativamente alterada, graças ao surgimento da escola (numa perspectiva mais formal) a partir do Século XVII, no qual as famílias passaram a ter uma preocupação bem maior no que diz respeito a educação de seus filhos. Assim, o período medieval foi marcado pela forte atuação da Igreja Católica que difundido o evangelho e pregando os princípios cristãos, defendia a união de pessoas pelos laços do matrimônio, o que significou o crescimento do número de famílias.

É importante destacar que a partir do Século XVIII esses privilégios que eram dados aos filhos mais velhos foram sendo questionados e de certa forma vencidos, de modo que se sustentou o discurso de não se ter preferências por filho nenhum e que todos eram (ou pelo menos deveriam) ser tratados igualmente. Nesse sentido, Airès (2006, p. 162) considera que: "esse respeito pela igualdade entre os filhos de uma família é uma prova de um movimento gradual de família-casa em direção à família sentimental moderna".

Nesse sentido, Airès (2006) considera que é no século XVIII propriamente dito que as transformações no que diz respeito a instituição familiar começam a acontecer a partir da própria organização da casa onde esses sujeitos moravam, que passou a ser organizada com base em separações de cômodos: sala de jantar, sala de estar, corredor e dormitórios/quartos, que trouxeram mais intimidades para os membros das famílias. Pode-se dizer que a reformulações dos costumes determinaram a nova concepção de família e seu comportamento social. Sobre esse momento em particular, e também a consolidação histórica do agrupamento familiar, Picanço (2012, p. 08) informa que:

\begin{abstract}
Dessas novas famílias fazia também parte a descendência gerada que, assim, tinha duas famílias, a paterna e a materna. Com a Revolução Francesa surgiram os casamentos laicos no Ocidente e, com a Revolução Industrial, tornaram-se frequentes os movimentos migratórios para cidades maiores, construídas em redor dos complexos industriais. Estas mudanças demográficas originaram 0 estreitamento dos laços familiares e as pequenas famílias, num cenário similar ao que existe hoje em dia.
\end{abstract}

A partir da revolução industrial uma nova configuração familiar é instaurada, agora as famílias que migraram para as cidades passam a formar grupos pequenos, 
já que as fabricas presentes nas cidades atraíram muitas pessoas que abandonaram seus grupos para tentar mudar a sua realidade.

Fernandez (apud PEREIRA, 2008, p.49), entende que: "família é um termo que não é possível definir, sendo apenas possível a sua descrição, família é um conjunto de pessoas que gostam umas das outras". Com base no exposto, podemos considerar que a base para a compreensão do conceito de família a partir do século XIX diz respeito as relações afetivas e sanguíneas, pois são esses traços que vão demarcar os horizontes dos agrupamentos familiares.

Em síntese do que fora tratado até aqui sobre o conceito de família, podemos assegurar que as transformações sociais e históricas de determinado a própria forma de organização e também comportamental das instituições familiares, embora que se tenha como pilares de sustentação desse grupo, os sujeitos nucleares (pais e filhos). Isso se justifica especialmente no que diz respeito ao período compreendido entre o Império Romano e o Período Medieval, no qual as pessoas viviam sob o domínio de um único chefe de família (PICANÇO, 2012).

Nesse sentido, pode-se dizer que da modernidade para a contemporaneidade é que a família, enquanto instituição social tem sofrido suas maiores e mais significativas alterações tanto em termos de organização estrutural quanto da ideia de pertencimento ao grupo. Apresentam reflexões sobre esses períodos em particular, Phillips (apud HOHMANN; WEIKART, 2003, p. 46-47) considera que a família se configura como: "[...] um sistema ou uma cultura familiar como algo que envolve todas as coisas que as famílias fazem para levar as suas crianças a conhecer a compreender as ideias partilhadas pelo grupo familiar quanto a valores, crenças e comportamentos". Assim, a família a partir da modernidade passou a ser entendia como um grupo social que possuí objetivos comuns, muito embora ainda liga a questões puramente sanguíneas, mas que já admite questões relacionadas a valores, crenças e comportamentos.

Embora os agrupamentos sociais sejam por alguns autores considerados uma forma de família, no que tange a família natural considerada pelos institutos de pesquisa e estatística, pode-se dizer que ao longo dos tempos o número de membros vem sendo reduzido paulatinamente, como foi possível percebermos ao longo das reflexões até aqui propostas.

Não se pode deixar de considerar que a instituição familiar no que diz respeito ao seu cerne ou essência, nunca deixou de ser considerada, a primeira instância de 
socialização dos sujeitos, pois é a família que ajuda as crianças a dar os primeiros passos rumo a educação. Antes da entrada das crianças na escola, a família é a responsável por sua educação, que nos dias atuais tem se limitados mais aos princípios morais e valores sociais, que o próprio princípio educativo que tem sido relegado quase que exclusivamente para a instituição escolar. Pereira (2008, p. 43) considera que:

\begin{abstract}
A Família é considerada a instituição social básica a partir da qual todas as outras se desenvolvem, a mais antiga e com um carácter universal, pois aparece em todas as sociedades, embora as formas de vida familiar variem de sociedade para sociedade. A Organização das Nações Unidas (ONU) em 1984, refere a Família como o elemento de base da sociedade e o meio natural para o crescimento e o bem-estar de todos os seus membros.
\end{abstract}

Nesse sentido, relembrando o modelo educacional familiar presente especialmente no período medieval, pode-se dizer que houve apenas uma adequação na linguagem e compartilhamento da responsabilidade do ato de educar entre a escola e família, pois os primeiros saberes que são construídos pelos sujeitos são resultados de suas primeiras interações sociais que são desenvolvidas junto as famílias.

Nesse sentido, podemos afirmar que a partir das relações familiares, os sujeitos passam a integrar os grupos sociais maiores, mas sempre tomando como referência os saberes que foram inicialmente construídos. No entender de Felix (apud PEREIRA, 2008, p. 45):
A Família é, o primeiro e o mais marcante espaço de realização, desenvolvimento e consolidação da personalidade humana, onde 0 indivíduo se afirma como pessoa, o habitat natural de convivência solidária e desinteressada entre diferentes gerações, o veículo mais estável de transmissão e aprofundamento de princípios éticos, sociais, espirituais, cívicos e educacionais, o elo de ligação entre a consistência da tradição e as exigências da modernidade.

Considerando as reflexões e provocações elucidadas pelo autor, não podemos negar a ideia de que a família é um grupo social, e por isso subsidia relações de curto alcance para os sujeitos, ou seja, um olhar particular, restrito sobre elementos constantes no mundo.

Sobre o entendimento que se tem de família na atualidade e sua estruturação social, faz-se necessário recorrer ainda a Levy (2010) ao considerar que hoje a questão afetiva tem sido tomada como um dos parâmetros mais significativos para que se possa categorizar um agrupamento familiar. Pois, para o autor: "[...] a família se forma através do afeto e transforma seus seres a partir do afeto. Desta forma, 
são as relações familiares que despertam o entendimento baseado na compreensão e no carinho" (LEVY, 2010, p. 7).

Partindo dessa perspectiva, as relações afetivas, tornam-se central no que diz respeito aos agrupamentos familiares e isso vai respaldar os novos arranjos sociais que são tidos como família, como por exemplo, mães solteiras e filhos, pais solteiros e filhos, avós e netos, dois pais, duas mães, ou ainda casais que não possuem filhos, mais que juntos formam por vínculos afetivos uma família. Nesse sentido, as trocas afetivas são significativas nas relações que estão estabelecidas pelos sujeitos em seus grupos familiares, já que estas são carregadas por toda vida pelos sujeitos.

Considerando o exposto, podemos considerar que, a família embora seja um reflexo daquilo que acontece na sociedade, não reflete a realidade como um todo, mas sim fragmentos ou relações simplistas. Sendo assim, as relações dos sujeitos se complexificam a partir do momento que passam a integrar novos grupos sociais e educacionais que não estão restritos aos seus laços familiares. A escola é o principal grupo social nessa nova perspectiva dos sujeitos, por é a partir dessa instituição que os sujeitos têm a possibilidade de estar em contato com pessoas diferentes de seu grupo familiar.

\subsection{A redefinição do papel educativo da escola}

A categoria escola apresentam-se como uma tarefa simples (espaço onde as crianças são instruídas), se levam em consideração nossas experimentações socialmente empíricas e ao mesmo tempo complexa, considerada as dimensões sociais que essa instituição ocupa não apenas no que tange a sistematização dos sabres, mas especialmente sua intervenção na vida dos sujeitos, pois tudo vai depender em primeira instância da abordagem e da concepção que se tem ou se pode adotar do termo.

A primeira ideia de escola que se tem registro as civilizações Mesopotâmica e Egípcia tendo como finalidade sempre atender os interesses das elites. É verdade que com o transcorrer do tempo e o desenvolvimento de inúmeras teorias foi possível consolidar a universalização da educação, ao menos daquilo que se compreende por ensino básico, muito embora a escola e os processos formativos que desenvolvem estejam dispostos com base na lógica capitalista.

Com os filósofos gregos, não em termos de estrutura física, mas de educação por meio da filosofia que era desenvolvida em diferentes espaços, como, por 
exemplo, as praças públicas nota-se uma preocupação específica com a formação dos sujeitos que eram considerados cidadãos dentro daquele sistema (REVELAT, 2018). É importante destacar que nesse momento inicial, a educação é concebida a partir da ótica meramente abstrata e funcional, pois ainda não se tinha um método que legitimasse o conhecimento ali produzido como científico. Nesse sentido, Revelat (2018, p. 01) assegura que:

No mundo antigo a criança recebia aulas de um pedagogo em sua residência. Sendo assim, entrava em contato com a educação em seu sentido mais amplo, voltada para o ensinamento de valores e condutas sociais básicas. Essa mesma criança frequentava a escola para aprender habilidades instrumentais básicas, a saber: ler, escrever e calcular. Portanto, o ensino foi dividido em educação e instrução.

Podemos perceber que nessa sociedade a função da escola era apenas desenvolver junto aos sujeitos habilidades básicas, o que levou a segmentação entre educação e instrução, pois o conhecimento elementar era necessário apenas para que o sujeito dominasse a oralidade e a escrita bem como questões relacionadas ao cálculo. Nesse sentido, a ideia de escola que se tinha era muito restrita não apenas em termos de conteúdo, mas também dos sujeitos que poderiam frequentar esses espaços, já que nessas sociedades registra-se um índice elevado de sujeitos na prática do trabalho infantil.

Avançando um pouco mais no curso da história, assim como, fora feito com a instituição familiar, no Período Medieval, a Igreja passou a manter o controle sobre a instituição escolar, com destaque especialmente para a cristalização dos dogmas e saberes que eram necessários para que a lgreja mantivesse seu domínio sobre os fiéis. Ressaltamos que ainda que se perceba certos avanços no que diz respeito a forma de organização do saber e dos valores que eram difundidos, o ensino era ainda muito limitado as crenças e sabres de natureza moral e religioso.

Caracterizando esse momento em particular, Petitat (1994, p. 49) considera que: "[...] a civilização medieval é basicamente uma civilização da palavra e dos sentidos, em que a transmissão dos conhecimentos e das tecnologias prescinde das instituições especializadas e de textos escritos". Diante das considerações do autor, podemos considerar que é possível nesse momento perceber uma sistematização mais prática e objetiva do conhecimento, especialmente da escrita. Assim, a educação em sua dimensão formativa encontrava-se atrelada aos princípios religiosos e por consequência disso as escolas estavam sobre o controle e direção dos religiosos. 
Não se pode perder de foco que é também entre o século XII e XV que a sociedade europeia passará por profundas transformações em sua própria organização, dada a retomada das atividades ligadas ao comércio, o que foi responsável por desatrelar a educação da vida religiosa e as pequenas elites daquele período, pois diante dessa nova organização social com base na atividade comercial a necessidade que precisa ser atendida é a do próprio comércio, que primou pela construção e consolidação de uma escola de/para profissões.

Refletindo sobre esse momento de ruptura ou quebra de paradigma que marcou o final da Idade Média, Petitat (1994, p. 06) considera que foi a partir desse contexto que foi possível "[...] a escola generaliza a cultura escrita, segmenta-se em estágios e níveis; o diploma transforma-se em esperança de mobilidade, e o conhecimento científico, em esperança de libertação. Tomando como referência, os princípios defendidos pelo autor, pode-se dizer que não se percebe uma evolução da escola medieval para a moderna, mas ao contrário é possível notar uma ruptura, à medida que a escola moderna vai se constituindo e consolidando de forma gradual com base nas necessidades políticas, sociais e econômicas de uma classe que estava em ascendência, a burguesia.

A partir do movimento iluminista, a escola passou a ocupar-se mais com a instrução do que com a educação, já que essa era a necessidade apontada pelo contexto comercial que estava sendo desenvolvido. Um fato interessante no que diz respeito a esse novo momento da escola, refere-se à condição de acesso, pois antes a escola era um privilégio das pequenas elites e agora (séculos XIX e XX) diante da necessidade de qualificação de mão de obra o ensino escolarizado já era considerado obrigatório na maioria dos países do globo.

Isso se justifica pelo simples fato da escola sempre se apresentar como representante dos interesses das elites, assegurando a estes o domínio do conhecimento sistematizado produzido em seu interior, por isso não poderia se transformar de maneira instantânea e sem os devidos requisitos numa instituição verdadeiramente democrática. Esses momentos iniciais de redefinição do papel e da própria organização da escola fez com que fossem recordes os índices de evasão, dificuldades de aprendizagem e outros problemas relacionados à expansão do ensino, pois a maioria dos sujeitos que passaram a ingressar na escola não conseguiam se identificar com os saberes que eram difundidos ali dada a sua condição de exclusão histórica desse espaço (REVELAT, 2018). 
É importante salientar que as instituições ligadas a questão religiosa não foram abolidas, mas passaram por um processo de transformação, especialmente diante do pensamento iluminista, no qual a centralidade das reflexões deixa de ser Deus e passa a ser o próprio homem em sua materialidade. Merece destaque nesse momento a Reforma Protestante, que consistiu no questionamento da autoridade da Igreja Católica, especialmente no que diz respeito a catequização dos sujeitos baseada nos dogmas e vendas de indulgência e na consolidação obrigatoriedade da frequência e a permanência em termos cronológicos das crianças na escola (FRANCISCO FILHO, 2003, LUZURIAGA, 1969).

A partir da reforma protestante, a própria ideia sobre a infância e juventude fora alterada, à medida que se buscou superar a ideia da criança como um adulto em miniatura e consolidar a imagem da criança como sujeito frágil e indefeso que necessita ser submisso e obediente as normas, assim como, estar sob constante supervisão (PETITAT, 1994).

Entretanto, notamos que as revoluções: Industrial e Francesa tiveram um papel determinante para que a instituição escolar fosse reestruturada com vista a atender as necessidades dessa nova sociedade industrial que primava pela qualificação de mão de obra para ser absolvida pelas indústrias, ou melhor, pelo mercado de trabalho. Petitat (1994) considera que é a partir dessas revoluções e transformações que foram implementadas na sociedade que a educação passa a ser desenvolvida num prédio próprio, a qual se denominou escola, pois se fazia necessário se manter o controle sobre o desenvolvimento individual dos sujeitos, para assim classifica-los.

Com o florescimento do sistema neoliberal, a sociedade passou por significativas transformações, à medida que a mão de obra feminina passou a se tornar cada vez mais atrativa, pela própria desvalorização da figura da mulher (no recebimento de baixos salários), o que foi responsável por deixar a cargo das escolas, em especial as creches o papel de além de instruir, cuidar das crianças.

Para Alarcão (2001) a escola deve ser concebida como um espaço social que congrega em si múltiplas dimensões. Nesse sentido, podemos considerar que a escola se apresenta como um espaço de interação e troca de saberes, entre sujeitos sociais distintos, como por exemplo, alunos e professores. Dessa forma, a escola pode ser ainda concebida como uma instituição social que tem como a função ou mesmo a missão de contribuir significativamente para a transformação da realidade 
dos sujeitos. Assim, a escola dentro da lógica do capital atua a partir de dois vieses que são eminentemente dialéticos (contraditórios) que é a formação para atender as necessidades de mão de obra qualificada em certas especializações tal qual requer o mercado de trabalho e também a formação dos sujeitos para a transformação de sua realidade social e superação de suas mazelas.

Tomando como referência as reflexões propostas por Alarcão (2001), Pires (2001) considera que nos dias atuais a escola tem assumido para si inúmeras responsabilidades, que na prática nem sempre lhe convém, mas isso é resultado das necessidades do sistema capitalista, que ao absolver o grupo familiar em atividades comerciais e mercadológicas, deixa sob responsabilidade da escola a função de educar, instruir e cuidar (além das necessidades básicas; físicas e biológicas, inclui-se ainda os aspectos relacionados a afetividade que não pode ser conduzida pelos pais que passam a ver seus filhos poucas vezes, em razão das duras jornadas de trabalho).

Sendo detentora de um papel social relacionado a formação dos sujeitos, a escola é sem dúvida a materialização das expectativas criadas pelas famílias em realização profissional. Nesse sentido, entendemos que o desenvolvimento da sociedade e das famílias, em sua amplitude depende das práticas educacionais e culturais disseminadas nas instituições formativas (escolas). Refletindo sobre essa possibilidade, Pires (2007, p. 29) advoga que:

\footnotetext{
A filosofia unificadora da escola deve ser a de estabelecer políticas coerentes a serem aplicadas no estudo de situações reais e específicas, capazes de colaborar para a melhoria das condições de vida das comunidades abrangidas pela sua ação.
}

Pires (2007) olhando para a escola como uma instância formativa de grande relevância em nossa sociedade considera que atividades por ela desenvolvidas devem se dá de maneira integrada e em parceria com a família. Sendo assim, o papel da escola passa a incluir não apenas o processo de ensino-aprendizagem refletidos na relação professor-aluno, mas também a relação com as famílias, haja vista, que se espera que a escola seja uma forma imediata de superação das desigualdades sociais.

A escola como produto da sociedade sofre diferentes influências contextuais, como por exemplo, a do desenvolvimento técnico-científico e das necessidades oriundas do sistema capitalista. Pires (2007, p. 30) considera que: "[...] deve 
exercitar sua função crítica ao estudar os principais problemas que interferem em sua localidade, devendo apontar soluções". Assim, a escola caminha diante das dinâmicas sociais da realidade em direção a um caminho de duplo sentido, ora formando as pessoas para integrarem o mercado de trabalho e ora formando a consciência crítica dos sujeitos para a transformação de sua realidade.

\section{OS DESAFIOS DA RELAÇÃO FAMÍLIA E ESCOLA NA ATUALIDADE}

Pensar a relação família e escola na atualidade implica considerar os desafios que estão sendo postos para a construção do conhecimento nesse sentido, nessa sessão apresentaremos os dados coletados junto a pais e professores da rede municipal de educação de Cametá sobre como percebe e como vem sendo desenvolvida a relação família-escola.

Durante o processo de coleta de dados buscamos inicialmente saber como estão estruturadas as famílias dos alunos atendidos na rede municipal de educação de Cametá, constatamos ao final da fala de todos os entrevistados que foram 13, que as escolas da rede municipal de educação lidam com uma organização familiar complexa sendo muitas vezes formadas por mães solos e filhos, avós e netos, tio e sobrinhos, entre outros. Sendo assim, a escola tem a responsabilidade de ser um espaço inclusivo e abarcar a diversidade de composição familiar que hoje é uma realidade de nossa sociedade.

Também inquerimos os pais sobre o que esperam da escola para seus filhos, as respostas a esse questionamento foi unanime dos 13 entrevistados destacando que esperam um ensino de qualidade que, tenham acesso a um conhecimento capaz de mudar suas vidas. Percebemos nesse sentido que, a crença na escola é muito grande, mas também podemos identificar responsáveis de alunos que cobram uma participação mais ativa na escola como por exemplo, o $\mathrm{F}^{2}{ }^{2}$ que afirmou: "Eu esperava algum tipo de projeto que ensinasse alguma coisa para os adolescentes de hoje. As escolas junto com a família poderiam se unir um pouco mais".

Levando em consideração recorremos a Kléin e Pátaro (2018, p. 03), que analisam o papel que deve ser assumido pela escola na formação dos sujeitos. Sendo assim:

\footnotetext{
${ }^{2}$ Essa denominação é utilizada para registrar o pai/mãe ou responsável de alunos entrevistados para a construção desse trabalho.
} 


\begin{abstract}
A escola cumpre uma função social essencial à formação dos novos cidadãos, na medida em que os saberes selecionados por uma sociedade e os seus valores serão transmitidos e construídos mediante ações educativas. Nesta instituição nossas crianças e jovens permanecem quatro horas por dia, cinco dias por semana, nove meses por ano e ao menos doze anos de suas vidas. Trata-se da única instituição social por qual passa obrigatoriamente toda a população infantil e juvenil. A incidência da escola sobre a vida das crianças e dos jovens não se restringe às horas em que permanecem na instituição, prolonga-se para além deste tempo, compreendendo o desenvolvimento de atividades como tarefas, estudo, trabalhos em grupo, etc.
\end{abstract}

Com base nos autores, constatamos que a escola é de fundamental importância no processo de formação dos sujeitos, pois as influências que exerce sobre os alunos vai além do tempo necessário a escolaridade como bem descreve, mas fica e se desenvolve na própria conduta dos sujeitos. É importante salientar ainda, que a escola mesmo sendo uma instituição responsável pela formação dos sujeitos, não pode responder sozinha pela educação das pessoas, pois seu papel social e formativo é limitado, o que requer da família grupo social com quem os sujeitos têm mais contato e trocas sociais atue de maneira coparticipava, tal como disciplinam a Constituição Federal de 1988, o Estatuto da Criança e do Adolescente (1990) e a LDB 9.394/96 que a educação é dever do Estado (na garantia da oferta dos níveis de ensino) e da família (garantia regularidade de frequência a aula e acompanhamento).

Para compreender o olhar que a escola tem sobre a família, entrevistamos 06 professores sobre como a composição familiar e a presença da família na escola contribuem ou interferem no processo de aprendizagem dos alunos. Sendo assim, questionamos os professores se: A composição familiar faz diferença no comportamento e aprendizagem do aluno na escola? A maioria dos professores disse que interfere significativamente, contudo, o PF7 ${ }^{3}$ alegou que, a estrutura familiar tem poucas influências sobre o comportamento dos alunos quando colocamos em xeque as condições socioeconômicas das famílias. Isso significa dizer que mesmo a família estando situada no plano nuclear (família tradicional: Pai, Mãe e Filhos) se as condições básicas de saúde, alimentação e educação não estiverem asseguradas, os comportamentos dos alunos sofrem de forma determinante interferências que são prejudiciais aos seus aprendizados.

\footnotetext{
${ }^{3}$ Sigla utilizada para identificar os professores que contribuíram com a pesquisa sem que sua identidade fosse revelada, pois assinamos um termo de sigilo e ética no uso das informações perante os entrevistados.
} 
Genofre (1997) considera que com o processo de evolução das famílias, a hierarquização vai aos poucos cedendo espaço para as relações afetivas, as pessoas formam uma família por afeição mútua, o que nos leva a compreender que não é a forma pela qual a família se estruturou em termos de membros, mas sim os objetivos e horizontes que essa família tem, ou seja, como a família acompanha o aluno tanto em sua vida diária, como escolar.

Outro questionamento que fizemos aos professores foi: Como deve ser a participação da família na escola? As respostas a esse questionamento foram quase todas alinhadas no sentido de dar condições de estudo e qualidade de vida escolar aos filhos, participar de reuniões e auxiliar seus filhos na produção e realização de atividades escolares. Entretanto, a resposta do PF6 nos chamou a atenção ao dizer que os pais devem participar: "Vindo trazer o filho na escola, participando das reuniões, vindo mesmo sem ser chamado para verificar se o mesmo está assistindo as aulas, conversar com o professor mostrando interesse em relação a aprendizagem da criança etc".

Essa concepção foge a lógica capitalista impregnada na concepção de todos os outros professores, pois a ideia de família que se tem na sociedade capitalista é de sujeitos sem tempo e com uma vida corrida e intensa. Em decorrência dessa rotina, segundo o autor, a família abdicou de seus direitos e responsabilidades educativas, deixando todo esse processo a cargo da escola e seus profissionais. Isso criou um afastamento entre família e escola, bem como empoderou os docentes sobre o que e como ensinar na escola, pois possuem formação que na maioria das vezes os pais não tem.

Contudo, autores como Paro (2007), consideram que nos dias atuais, a escola se tornar um espaço aberto para o diálogo criando dessa forma estratégias e métodos que visem aproximar cada vez mais a família do contexto educacional, pois esta tem muitas informações que se considera significativa para a concretização de seus objetivos formativos, daí a importância dos pais estarem presente na escola para acompanhar o desenvolvimento de seus filhos mesmo quando não são convocados ou em momentos e situações programadas.

Verificamos que as famílias pouco participam fora do cronograma estabelecido pela escola. Isso requer que a escola e seus profissionais criem um espaço constante de diálogo e formação para estimular cada vez mais a participação dos pais e responsáveis na escola. Bordenave (1994) salienta que esse 
processo é importante, pois a participação ocorre de muitas maneiras, geralmente esperamos que ela ocorra de forma espontânea, contudo, quando não se processa dessa forma, a instituição escolar deve por meio de seus profissionais criar situações em que a família se perceba parte do processo e participe ativamente da ação, não apenas no sentido de estar presente, mas contribuindo em todos os processos que se desenvolvem na escola, desde o planejamento/elaboração até o processo de tomada de decisão.

A escola encontra dificuldades em abrir mão do papel de delimitar as diretrizes e caminhos a serem assumidos por todos no processo educacional, isso muitas vezes distancia as famílias da escola que, são levados a escola apenas para serem comunicados do comportamento indisciplinado de seus filhos e dos cronogramas de atividades, mas não para participar das decisões, organizações e planejamento das ações a serem implementadas. Para que os pais e responsáveis de fato participem das atividades escolares se faz necessário que estes desenvolvam:

\begin{abstract}
O sentimento de pertencimento [que] visa conscientizar as pessoas de que a escola não é um departamento privado, mas patrimônio público entenda-se, aqui, o legítimo direito ao letramento, à formação gradual, à cultura, à cidadania e a tudo o mais que interfira de forma positiva na vida individual e coletiva. O sentimento de pertencimento fortalece a valorização da escola na vida de cada um, cria identificação e responsabilidade recíprocas. (SÃO PAULO, 2005, p. 153).
\end{abstract}

Nestes termos, é preciso que a escola como instituição responsável pela produção e socialização do conhecimento estimule nas pessoas o sentimento de pertencimento, para que as responsabilidades educacionais sejam compartilhadas e que melhorias educacionais no que tange ao processo ensino-aprendizagem estejam asseguradas. Consideramos que diante das repostas ao questionamento lançado, a escola e seus profissionais, necessitam repensar estratégias e ações que aproximem cada vez mais a família do cotidiano da escola. Trata-se, portanto, de estabelecer uma relação de parceria, não uma relação de ajuda, no qual a família só participa quando a escola solicita algo. É preciso que a família esteja presente e integre o processo de toda de decisão e não seja uma muleta para a escola que aparece na instituição somente quando requisitada.

$\mathrm{Na}$ atualidade as instituições escolares tem trabalhado com uma ideia de uma gestão democrática, mas ainda não conseguiram de fato alcançar tal objetivo, pois a muito tempo a gestão democrática vem discutida por Paro (2007), que considerou 
que essa forma de gestão só se consolida com a implementação de dispositivos que assegurem a descentralização do processo de tomada de decisão e a garantia da participação dos sujeitos, não se trata de qualquer participação, diz respeito ao fazer de tomar e tornar-se parte numa ideia de pertencimento.

$\mathrm{Na}$ contramão do pensamento supracitado, notamos no desenvolvimento dessa pesquisa que, há uma dificuldade relativa tanto da parte dos pais quanto dos professores no que diz respeito as formas que as famílias podem fazer uso para auxiliar seus filhos nas atividades escolares. Em todos os dois grupos percebemos que o papel das famílias na escola está condicionado ao auxílio dos filhos nas atividades em casa e ainda, acompanhar a rotina dos filhos na escola para saber de seu comportamento. Não foi possível identificar em nenhum dos grupos uma concepção em que a família passe a fazer parte da escola no sentido de tomar parte, de assumir a responsabilidade de também pensar e decidir sobre os caminhos que devem ser assumidos pela escola no que tange a formação escolar dos alunos.

\section{CONSIDERAÇÕES FINAIS}

Assumir uma postura de escola democrática significa tornar viável e possível a participação de todos no processo de tomada de decisão, especialmente dos pais e responsáveis de alunos que por muito tempo relegaram a escola a função única de educar seus filhos em voga da concepção de escola que se tinha. É importante frisar que mudanças estão ocorrendo na sociedade e na forma de pensar a educação escolar e, a relação família e escola passou a ser vista como condição fundamental para o desenvolvimento pleno e integral dos alunos.

Sendo assim, família e escola necessitam, a cada momento, encontrar estratégias que superem as suas dificuldades, construindo uma identidade própria e colectiva, agindo em sintonia como agentes facilitadores do desenvolvimento pleno das crianças e dos jovens. No momento em que escola e família conseguirem estabelecer uma parceria, ou mesmo se integrarem no alcance de seus objetivos para com os alunos/crianças que são comuns, muitos dos conflitos hoje observados em sala de aula, serão aos poucos superados. Todavia, para que isso possa aconteça é necessário que a família realmente participe da vida escolar de seus filhos, que se comprometa e se envolva com a escola, gerando assim, na criança/jovem, um sentimento de amor, sentindo-se amparada e valorizada como ser humano. 
Tanto a escola como a família possuem seus valores e os seus objetivos específicos face à educação da criança/jovem constituindo, no entanto, uma estrutura intrínseca, onde quanto mais diferentes são, mais necessitam uma da outra. Desse modo, cabe a toda à comunidade, não apenas aos setores relacionados com a educação, transformar o cotidiano da escola e da família, o que pode fazer através de pequenas acções modificadoras, para que se compreenda a importância dos objetivos traçados pela escola, assim como o papel da família como co-responsável nesse processo.

Um caminho seguro para tal propósito diz respeito, a descentralização das ações desenvolvidas no seio da escola, ou seja, é o estabelecimento de um modelo de escola e gestão democrática, no qual os pais não apenas figuram como visitas, muitas vezes indesejadas por questionar certas situações, mas como um espaço do qual as famílias fazem parte e se sentem parte e por isso integram essa vivência escolar a sua rotina. Contudo, como bem alertou Bordenave (1994) em muitos casos para que a participação (participar da ação) aconteça se faz necessário que a escola estimule tal processo, por meio de estratégias que preconizem aos sujeitos se sentirem parte da escola, opinando e contribuindo dentro de suas possibilidades no processo de tomada de decisão e nos rumos que a escola deve tomar quanto a formação dos filhos/alunos.

\section{REFERÊNCIAS}

ALARCÃO, I. Escola Reflexiva e Supervisão: uma escola em desenvolvimento e aprendizagem. Porto: Porto Editora, 2001.

ARIÉS, Philippe. História Social da Criança e da Família. Rio de Janeiro: LTC, 1981.

BORDENAVE, J. E. D. O que é participação. São Paulo: Brasiliense, 1994.

DEMENECH, Flaviana. Famílias: Diferentes concepções históricas. IN: X Encontro Regional Sudeste de História Oral - Educação das Sensibilidades: Violência, desafios contemporâneos. Unicamp; Campinas, de 10 a 13 de Setembro de 2013.

FRANCISCO FILHO, Geraldo. História geral da educação. Campinas, SP: Editora Alínea, 2003.

GENOFRE, R.M. Família: uma leitura jurídica. In: A família contemporânea em debate. São Paulo: EDUC/Cortez, 1997. 
HOHMANN, Mary e WEIKART, David P. Educar a Criança. Edição da Fundação Calouste Gulbenkian: Lisboa, 2003.

KLEIN, Ana Maria; PÁTARO, Cristina Satiê de Oliveira. A escola frente às novas demandas sociais: Educação comunitária e formação para a cidadania. PUC- São Pulo, $2018 . \quad$ Disponível em: $<$ http://www4.pucsp.br/revistacordis/downloads/numero1/artigos/1_escola_novas_de mandas.pdf>. Acesso em: 10/06/2021.

LEVY, Laura Affonso da Costa. Família Constitucional, sob um olhar da afetividade. 2010. Disponível em: <http://www.ambitojuridico.com.br/site/index.php?n_link=revista_artigos_leitura\&artigo_id=7438>. Acesso em: 07/06/2021.

LUZURIAGA, Lorenzo. História da educação e da pedagogia. São Paulo: Companhia Editora Nacional. 1969.

PARO, Vitor. A gestão democrática da escola pública. São Paulo: Editora Ática, 2007.

PEREIRA, P. A. Desafios Contemporâneos para a Sociedade e a Família. In Revista Serviço Social e Sociedade. № 48, Ano XVI, 2008.

PETITAT, André. Produção da escola/produção da sociedade: analise sóciohistórica de alguns momentos decisivos da evolução escolar no ocidente. Porto Alegre: Artes Médicas, 1994.

PICANÇO, Ana Luísa Bibe. A relação entre escola e família: as suas implicações no processo ensino-aprendizagem. Escola Superior de Educação João de Deus, Lisboa, 2012.

PIRES, Pierre André Garcia. A escola e sua contribuição na formação de sujeitos: um olhar a partir da nova concepção de currículo; Anais do VI Congresso de Letras: Linguagem e Cultura: Múltiplos Olhares, 2007.

REVELAT, Tássio. O surgimento da Escola e as suas funções sociais. Disponivel em: <https://rl.art.br/arquivos/1952889.pdf>. Acesso em: 10/06/2021.

SÃO PAULO (Estado). Secretaria de Estado da Educação. Escola da Família. Série Idéias, №. 32. São Paulo: FDE, 2004. 